\title{
Effects of Covid-19 on Language Performance of Pakistani Secondary School Students
}

\author{
Hayat ullah $^{1}$ Rose Patsy Tibok ${ }^{2}$ Dr. Jane Wong Kon Ling ${ }^{3}$
}

*PhD student, Centre for promotion of knowledge and language learning, Malaysia Sabah University (UMS) Email: haytfcm28@gmail.com

*Centre for promotion of knowledge and language learning, Malaysia Sabah University (UMS) Email: rose.tibok@ums.edu.my

*Centre for promotion of knowledge and language learning, Malaysia Sabah University (UMS) Email:

jane@ums.edu.my

DOI: 10.29322/IJSRP.11.06.2021.p11418

http://dx.doi.org/10.29322/IJSRP.11.06.2021.p11418

\begin{abstract}
The Government of Pakistan closed all the educational institutions on March 14, 2020 due to the spread of the pandemic Covid-19. The imposition of control movement and closure of institutes was implemented at the time when the secondary school students in district Mardan were appearing for their annual examination 2020. The increase of COVID cases across the country extended the closure of the educational institutions for the academic year 2020 and all the students were promoted to the next grade without examination which was another impact of COVID on students' English language performance. The government of Pakistan advised to carry out educational activities through online classes which were difficult for government school students and teachers that stopped the interaction of students and teachers. It is hypothesized that the abrupt cancellation of examinations and break in academic activities would negatively affect the students' performance in English language at the secondary school level. In order to know the effect, data were collected from three government high schools in district Mardan by interviewing three English teachers from each school. Semi-structure interviews were conducted via mobile phone for enquiring about their views about the effects of COVID-19 on students' language performance. The results revealed that there is likely to be a drop in English language performance of secondary school students if the COVID-19 could not be contained considering the untimely closure of the institutes during the academic session.
\end{abstract}

Key Words: English Language performance, Effects of Covid-19 on Language

\section{INTRODUCTION}

This article is to investigate the effects of COVID-19 on English performance of Pakistani government secondary school students. Amid the fears of coronavirus outspread, that had reportedly started from China, US, Italy and other parts of the Europe, the ministry of education of Pakistan, with consultation of doctors and NCOC (National Command and Operational Centre) unanimously decided to close all the educational institutions including, schools, colleges and universities in mid of March 2020 (Notified country wide). Since 
it was the end of the academic session 2020 in all public and private schools therefore, the students were promoted to the next class without annual examination. In the history this happened for the first time across the world that the educational institutions were to close because of a disease. The closure was only for two weeks but unfortunately it extended to the entire session and the students could not attend their face to face classes in Pakistan that has adversely affected their academic performance. In order to keep the students touch with academic activities the government of Pakistan advised the head of the educational institutions to carry out online classes and homework assignments (Notified by the government of Pakistan). This practice was somehow successful in private or public institutions but the government school students could not be benefited due to non-access of technology and internet facilities. The government school students were called to schools for assigning of home work by their respective teachers on staggered routine following SOPs.

Very less research is there in terms of educational activities during disease especially in English language performance it is equal to zero, however research about COVID-19 is somehow exists (Chinazzi et al., 2020; Hopman, Allegranzi, \& Mehtar, 2020; Kraemer et al., 2020; Wu \& McGoogan, 2020; Zu et al., 2020). Less research doesn't mean that COVID-19 has no effect on education but as a matter of fact studies in education rarely incorporate effects of disease on the effective provision of education to learner across the world. The rapid increase in COVID-19 cases not only affected education rather every activity of human life has been disturbed.

However experts in medicine are working across the world to find a solution to this pandemic and they have somehow succeeded in introducing vaccine which is carried out across the globe. It is hoped that in Pakistan maximum people will be vaccinated at the end of 2021. All the business activities are stopped due to restrictions on moments due to which economists are working to manage the country economy. The disease started in China, Wuhan and reached to every county in the world surprisingly in a short span of time (Wickramasinghe et al., 2020). The third wave of COVID-19 started in the mid of March 2021 and surprisingly increased daily positive cases and deaths in Pakistan which turned the situation that the government again closed the educational institutions recently reopened at the start of 2021. The government of Pakistan launched various projects to contain the spread of the pandemic with timely intervention measures such as closing markets, banning public transport and imposition of SOPs by the people.

\section{COVID-19 and English Language}

The government decision of closure of the educational institutions was to reduce the risk of spreading COVID-19 to the children across the country. The abrupt closing of secondary school also was a positive response by the government of Pakistan in order to save the students from the possible risk of COVID-19 as in school many people assembled which is dangerous for rapid spread of the pandemic. The effect of COVID19 was on the low economic countries and schools have lesser effects as the academic activities could be carried out in December or later. The gap in academic activities at secondary level however, mostly affected in terms of English language performance.

The purpose of this research study was to know the views of the English teachers about the English language performance of their students in course of the closure of school. This study will help the ministry of education to get information regarding students' performance in English language during COVID-19 and plan preparedness to contain the effects of this pandemic. This study will also help the other branches of education 
to get prepared for the effects of pandemic and plan alternate necessary arrangements other than face to face learning.

In Pakistan English language is taught as compulsory subject at secondary level. The prescribed text book for English language develop students English language skills in the entire academic session. All the activities pertaining to the attainment of English language skills are planned which sometime disturbed by health problem of an individual but this time the practice of closing institution due to pandemic occurred for the first time in the history. Since the COVID-19 compelled the government to close the educational institution untimely which would have far reaching consequences. In the present situation in which the government has closed all the institution to control the spread of COVID-19, the English language activities are stopped due to which the students learning process has badly affected. The English language performance in government schools at secondary level is thought to be passive and the effect of COVID-19 will likely rollout the existing capability of the government secondary school students in Pakistan.

Therefore, this research study is a step to contain the effects of COVID-19 in English language performance at government secondary school students.

\section{Significance of the study}

The study is significant for research in language as it provide a valid and important literature to language and educational research. It also provide information to the ministry of education to prepare strategy and planning for the effects of COVID-19 on English language performance at government secondary school level. The study is important as it is a contribution towards the educational research as it provides a valid literature to linguistic research that could be useful for educational research and language particular in future study.

\section{Research Problem}

The untimely closure of the academic institutions to control the spread of COIVD-19 disturbed the academic activities at secondary school level. The purpose of this research study is to find out the Effects of Covid-19 on Language Performance of Pakistani Secondary School Students.

\section{Research Objectives}

1. To know the effect of COVID-19 on English language performance of secondary school students

2. To find out possible reasons to overcome the English language performance affected because of COVID-19 of secondary school students

\section{Research Questions}

1. To what extant COVID-19 affected students' performance of English language at secondary level?

2. What possible measures can be taken to overcome the English language performance drop due to COVID-19 of secondary school students?

\section{Methodology}


The methodology used for this research was qualitative method of research. The methodology was adapted from Creswell (2017), a case study approach was used.

\section{i. Participants}

Participant of the study were nine English teachers, teaching to secondary school students randomly selected from three government high schools. Interview data was collected from nine English teachers from government schools in district Mardan (Pakistan). For selection of the participants the following criteria was used on account of;

a. English teachers teaching to secondary school students in government school in district Mardan (Pakistan).

b. Having ten years of teaching experience at government secondary schools.

c. Having basic knowledge of Coronavirus and information about SOPs.

\section{ii. Research instruments}

The instrument used for data collection was semi-structured interview developed by the researcher. There were ten items in the semi-structured initially. The semi-structured interview was then validated from two experts. The experts agreed only on eight items. The two items were then removed.

\section{iii. Data collection and Analysis}

Mobile phone was used for interview as the government had announced lockdown and strictly banned on movements. The people were advised for self-isolation and to keep social distancing by the government. All the semi-structured interviews were sent to English teachers using Whatsapp application for which an android cell phone was used by the researcher. All the nine English teachers responded to the interview and returned the filled interview questionnaire via Whatsapp to the researcher. Their responses were later on discussed to all the English teachers on voice calls for validity and reliability of the data.

\section{Results}

The results of the semi-structured interview collected from the participants, indicate that there will be likely a drop in the performance of the secondary school students in English language. This drop in the performance of the students' English language is due to their short time of contact with their teachers that occurred due to following COVID-19 SOPs and the closure of the institutions. The English teachers responded to a question asked about the effects of COVID-19 on students' performance on English language; maximum responded that the sudden closure of the schools have far reaching effects of English language performance on government secondary school students. In a response to a question regarding how much students are likely to be affected by COVID-19, the researcher received maximum information that school provides a conducive atmosphere to the students which has been badly affected by sudden closure of institutions due to which students' English language performance would be affected. The participants were of the opinion that the students' English language performance of secondary school students could not be recovered as it was a closing time of their academic session. However, some of the respondents agreed that if a speedy plan is devised and regular classes started with special attention then this loss can be recovered somehow. The participants were of the opinion that online classes at secondary school level if initiated can reduce the loss in English language performance met during COVID-19. In a response to a question as "Is there any alternative other than face to face classes", majority of the participants agreed on using mobile apps, such as Whatsapp, Facebook, Zoom, Google class room and Television programs. The participants suggested 
that the government should immediately arrange online classes for speedy recovery of the students' English language performance. In a personal capacity the English teachers at government schools communicate to their students via Whatsapp occasionally which they say that all students are not connected. Very few students are connected with their teachers using mobile phone.

\section{Conclusion}

Based on the information received from semi-structured interview from English teachers of government secondary school at district Mardan, Pakistan, it is concluded that students at secondary level have been badly affected in terms of their English language performance due to the sudden closure of academic activities in order to control the spread of COVID-19 throughout the country. The schools provide a conducive atmosphere to the students for improving their English language performance as well make them regular. The untimely closure of the schools interrupted the students' regularity as well as academic activities. Moreover, in Pakistani government schools there is no alternative other than face to face learning. The students need to be connected with academic activities. The only solution to the issue is to start online classes in government schools in Pakistan to reduce further loss in academic as well as English language performance at secondary level.

\section{Recommendations}

The study recommends the following measures to be taken in order to reduce the effects of COVID-19 on English language performance at secondary school level in district Mardan, Pakistan.

i. Online classes may be initiated immediately. Special attention needs to be given to the students English language performance at secondary level.

ii. English teachers at secondary level may be trained to carry out online classes.

iii. Immediate and prompt action may be taken to ensure internet access to all the government schools in district Mardan.

iv. If possible schools may be reopened following strict SOPs and an intervention program may be launched to recover students' loss in English language performance.

v. It is also recommended that the government should devise strategy to face challenges such COVI-19 in future.

vi. $\quad$ Further study also needed keeping in view other academic activities.

vii. Further research can be done in other areas of Pakistan.

\section{References}

Chinazzi, M., Davis, J. T., Ajelli, M., Gioannini, C., Litvinova, M., Merler, S., ... Viboud, C. (2020). The effect of travel restrictions on the spread of the 2019 novel coronavirus (COVID-19) outbreak. Science. https://doi.org/10.1126/science.aba9757

Hopman, J., Allegranzi, B., \& Mehtar, S. (2020). Managing COVID-19 in Low and Middle income Countries. JAMA. https://doi.org/10.1001/ jama.2020.4169 
Kraemer, M. U., Yang, C. H., Gutierrez, B., Wu, C. H., Klein, B., Pigott, D. M., ... Brownstein, J. S. (2020). The effect of human mobility and control measures on the COVID-19 epidemic in China. Science. https://doi.org/10.1126/science.abb4218

Wu, Z., \& McGoogan, J. M. (2020). Characteristics of and important lessons from the coronavirus disease 2019 (COVID-19) outbreak in China: summary of a report of 72314 cases from the Chinese Center for Disease Control and Prevention. JAMA. https://doi.org/10.1001/jama.2020.2648

Zu, Z. Y., Jiang, M. D., Xu, P. P., Chen, W., Ni, Q. Q., Lu, G. M., \& Zhang, L. J. (2020). Coronavirus disease 2019 (COVID-19): A perspective from China. Radiology, 200490. https://doi.org/10.1148/radiol. 2020200490 